\title{
Transitioning Education and Training to a Virtual World, Lessons Learned
}

\author{
S. Charlie Dey ${ }^{1}$ \\ charlie@tacc.utexas.edu \\ Je'aime Powell ${ }^{1}$ \\ jpowell@tacc.utexas.edu \\ Brandi Kuritz ${ }^{1}$ \\ bkuritz@tacc.utexas.edu
}

\author{
Victor Eijkhout ${ }^{1}$ \\ eijkhout@tacc.utexas.edu \\ Susan Lindsey ${ }^{1}$ \\ slindey@tacc.utexas.edu \\ Joshua Freeze ${ }^{1}$ \\ jfreeze@tacc.utexas.edu
}

\author{
Lars Koesterke ${ }^{1}$ \\ lars@tacc.utexas.edu \\ Rosalia Gomez ${ }^{1}$ \\ rosie@tacc.utexas.edu
}

\begin{abstract}
Interaction is the key to making education more engaging. Effective interaction is difficult enough to achieve in a live classroom, and it is extremely challenging in a virtual environment. To keep the degree of instruction and learning at the levels our students have come to expect, additional efforts are required to focus efforts on other facets to motivate learning, whether the learning is relative to students in our academic courses, student internship programs, Summer Institute Series, or NSF/TACC's Frontera Fellowship Program. We focus our efforts in lecturing less and interacting more.
\end{abstract}

Interaction now comes in the form of:

- $\quad$ taking a more casual approach to teaching

- gamifying the classroom

- giving students more choices regarding the path the curriculum follows

- constantly relating the educational material to the students' current and future projects

- $\quad$ flipping the lessons where the students apply concepts in class

- $\quad$ integrating peer programming groups

- taking advantage of all the technology options at our disposal

We have refocused our efforts on interacting with students using alternative means. As a result, we have built a successful academic and training curriculum, making our virtual classrooms more engaging and more collaborative, thus delivering a better educational experience.

This paper will detail those efforts, what worked well, what aspects needed adjusting, how those adjustments were implemented, and how those efforts were received by our students.

\footnotetext{
${ }^{1}$ Texas Advanced Computing Center (TACC), Austin, TX
}

Permission to make digital or hard copies of all or part of this work for personal or classroom use is granted without fee provided that copies are not made or distributed for profit or commercial advantage and that copies bear this notice and the full citation on the first page. To copy otherwise, or republish, to post on servers or to redistribute to lists, requires prior specific permission and/or a fee. Copyright @JOCSE, a supported publication of the Shodor Education Foundation Inc.

(C) 2021 Journal of Computational Science Education DOI: https://doi.org/10.22369/issn.2153-4136/12/2/3

\section{RATIONALE}

TACC has a wide array of training and educational offerings, aimed at everyone from IT professionals to research scientists to graduate and undergraduate students to high school and elementary school students. Our approach to training and education is very similar no matter the audience, to build a sense of community.

Teacher-student interaction is important. The more interaction there is, the stronger the learning experience can be. To create a positive learning environment, capable of meeting all of the educational needs, teachers must build a positive relationship with their students. Positive teacher-student interaction can be defined by shared acceptance, understanding, engagement, trust, respect, care, and cooperation. In a face-to-face classroom, this is a much simpler task. Trying to build a community with students online, can be more of a challenge.

For this reason, TACC took a step back on our traditional approach, and through an iterative process, reimagined the classroom while still providing representation, recognition, understanding, intimacy, expectation, respect, care, and cooperation to bring the aforementioned community together online. By taking a more casual approach to teaching with multiple instructors and then integrating aspects of gamification, loosening the curriculum, applying lessons to current events, spending more class time focused on applying learned concepts versus lecturing on concepts, breaking the class into groups to make learning more intimate, and using all available resources and technologies into our classes, we were able build the needed teacher-student interaction to create a positive learning environment.

\section{DISCUSSION}

\subsection{Casual Classroom}

When standing in front of a classroom, you have an automatic lead position where all students' eyes are upon you. It is easy to tell if students are paying attention or not, to read the classroom on how well they are understanding the material, when you should ask leading questions, when another example is in order, or when the students have reached their saturation point. This is not an easy task in the virtual classroom.

The virtual classroom requires a stronger relationship with students. By taking a casual or more informal approach to teaching, students feel more comfortable to ask and answer questions and ask for clarification. TACC implements this technique by utilizing multiple instructors in the classroom. The instructors work off one another. As one instructor focuses on the context of the lecture, the 
other instructors add to or highlight important concepts. This also allows the secondary instructors to conduct discussions and polls during the lecture to get a better read on how the class is absorbing the information, then bringing any items needing an immediate or more involved response to the attention of the primary instructor.

The secondary instructor also helps highlight any errors the primary instructor may make during any programming demonstrations. Keeping the comments and critiques light and in jest accomplishes three things. The errors in the code are brought to the students' attention and therefore more easily recognized in their own code. Students realize that everyone at every level makes mistakes. Lastly, students are more willing to open up, unmute their mics, and point out errors that the professor might have made, thereby making it so students are more willing to share their code and screens with the rest of the class and not be disconcerted about their error.

With a more casual approach to leading a class, having multiple instructors with secondary instructors leading discussions and polling the class during lectures, light conversations between the instructors, and pointing out errors during live coding examples, students are able to form a bond with the teachers and are more adept to learn and participate during class.

\subsection{Gamifying the Classroom}

Gamification is defined as the use of activities and external rewards to encourage motivation in non-game contexts. It is designed to increase a person's experience and engagement with a course, goal, or system. It helps bring a level of competitiveness and active participation to class, motivating students to learn. Gamification motivates people by making the learning process more enjoyable and engages the student more with a course.

Gamifying tasks are implemented in our courses and hackathons in particular. Sometimes the tasks are directly related to the learning process, and sometimes they are meant as an icebreaker to encourage students to open up. Some gamification tasks come as badges that students collect as they progress through the material and coding tasks. Other times, badges can be given to students who answer questions, ask questions, or share their screens and code with the rest of the class in order to get help debugging efforts. Students are also encouraged to hand out virtual badges to their peers, if a peer helps answer a question asked over chat.

Bringing healthy competition to the classroom can have positive effects, especially if it is a competition that helps move the class forward as a group instead of a competition between peers. This brings about a shared experience with mutual respect and cooperation.

\subsection{Open Curriculum In The Classroom}

Open curricula, where the student is open to take relevant courses in differing order with a faculty mentor, are normally associated with directing a field of study. This idea has been applied to our educational activities. Though each course and training activity conducted at TACC has set curriculum goals that need to be met, the route we take to achieve these goals can be fluid.

The experience of "open curriculum" classes allows students some freedom in how the course is directed and gives students some ownership regarding the course material. This helps create a culture of learning in which students display motivation, innovation, and self-direction. An open curriculum promotes independent thinking and creative problem-solving. We implement this with different types of projects and exercises during class time. Depending on how the students react to the different challenges presented, the next lesson can be modified to focus more or less on how the concept was received.

\subsection{Relating Material to Current Events}

Students need a personal connection to the material, bridging the new information with previously-acquired knowledge, or directly applying new knowledge with current world events. One of the keys to effective teaching is keeping the course material and projects relevant. It keeps the learning experience engaging. After key concepts are covered, the projects proposed for students to investigate are ones relative to current world topics, such as disease propagation, climate change, gerrymandering, and traffic patterns in urban settings.

By keeping projects directly tied to the world around them, students stay motivated, learning and retaining more of the material. Creative and critical thinkers work for work's own sake. They are driven by the desire to understand how the current world is progressing and where the world is heading. By being able to apply what they learn directly to real world issues, students achieve a better understanding of the role computational and data science plays in day-to-day issues.

\subsection{Flipping the Classroom}

Flipping the classroom is a response to the idea that class time can be used to engage students in learning through focused techniques, rather than through delivering lectures alone. By blending normal lectures with more student-centered learning strategies, instructors have more opportunities to deal with mixed levels of student comprehension, attend to any student difficulties, and differentiate learning preferences during in-class time. The amount of flipping varies from course to course, but for the majority of our training offerings, our courses integrate 20-30 minutes of hands-on activities through in-class exercises and less time lecturing. This allows us to turn the class into an active learning environment.

After key concepts of the course material are learned, the focus is turned to applying those concepts through in class challenges or group exercises. As student reactions to the challenges are observed, instructors can change the direction of the class based on these observations. This allows instructors to verify students are able to understand and apply their learned knowledge before moving to the next concept. These concepts are then built upon each other leading to a final project.

The flipped classroom environment allows students to better relate the material to previous lessons and apply the material to the future lessons. It also allows the instructors to make sure that the students have a good grasp of the content and are capable of working towards the major projects. This better engages the students and the instructors for a more productive classroom experience. The flipped classroom puts more control into students' hands regarding their own learning processes.

\subsection{Peer Groups and Paired Programming}

Another teaching approach implemented in our educational efforts is the use of peer groups and pair programming. Pair programming allows students to learn from one another and reduces the risk of going down an irrelevant path in trying to solve a problem. When properly implemented, this method allows students to learn from their peers. A student who may not be grasping a certain concept may achieve a better understanding when paired with a student who does. Due to the group environment, it also reduces the amount of effort required by the instructors to make sure all students are at an equal level. 
Taking advantage of technologies available, students are broken into pairs and assigned to a virtual space to communicate and collaborate within. Instructors will occasionally enter these spaces to see how students are progressing and answer any questions that may have arisen.

Another group activity in peered programming that TACC implements is "programming out loud." This technique enables students to clearly understand and articulate the complexities the coding tasks may require. They follow the instructor's lead to build an understanding of the coding steps involved to solve the exercise and then replicate the technique in their groups. The goal of this strategy, and all of our strategies, is to better engage students and instructors.

\subsection{Technology Options}

Classroom interaction is very important. To achieve this properly, every technical resource that enhances that interaction should be implemented. Technology can be used to enhance the dynamic between students and instructors. A combination of different technologies may be needed to sufficiently support a positive dynamic.

At TACC, we've used a combination of collaborative tools to enable students and instructors to better communicate. Zoom is used to conduct our training events, with breakout rooms for peer and paired programming sessions. Slack is utilized for students to engage with other students and instructors outside of normal classroom hours. Git and Repl.it are used for collaborative coding, while SSH is used to communicate with our classroom servers. This combination of tools allows students to be better connected to each other as well as the instructors, all in an effort to build a cohesive online, virtual community.

\section{LESSONS LEARNED, CONCLUSIONS}

When the class went virtual, a new approach to the classroom was very necessary. Progressive approaches to managing learning needed to be implemented in a short amount of time to best secure an accepting, understanding, and engaging environment where trust, respect, care, and cooperation exist. The approach we took at TACC included:

- taking a more casual approach to teaching

- gamifying the classroom

- giving students more choices regarding the path the curriculum follows

- constantly relating the educational material to the students current and future projects

- $\quad$ flipping the lessons where the students apply concepts in class

- $\quad$ integrating peer programming groups

- taking better advantage of all the technology options at our disposal

Unfortunately, there were some drawbacks during implementation, and it took multiple iterations to balance out the approach. Too casual of a classroom environment, and students lost some discipline and felt less pressure to get work in on time. We had to make sure that instructors maintained proper discipline through grading the material and holding students to due dates with some leniency. Gamification had a slight negative consequence with certain students who felt upstaged by others. To counteract this, we made sure that instructors kept lines of communication open with students who felt upstaged and made sure all students had an opportunity to interact in class. An open curriculum without a proper introduction to the concepts can slow down the course. Spending more time on key concepts actually can speed up the class because there are less interruptions on repeating core material. Occasionally the material can be dry, and making the material relevant is not always an option, but the concepts still need to be covered, and there is not much that can be done, aside from following up a dry lecture with some interactive lessons. Regarding flipping the classroom and peer programming groups, new and inexperienced programmers might require more of a traditional lecture from the instructor to better understand some concepts. We have found that by involving instructors within the peer programming groups, we can have "micro" lessons and still have the benefits of a flipped classroom and peer/paired programming.

Once a balance was attained, we were able to move our classes forward. We built an environment that encouraged interaction between students and instructors, leading to a stronger learning experience. This has led to a successful virtual training and education program.

\section{REFERENCES}

[1] Brame, Cynthia. "Flipping the Classroom." Vanderbilt University, Vanderbilt University, 26 Mar. 2020 , cft.vanderbilt.edu/guides-sub-pages/flipping-the-classroom/.

[2] Cox, Janelle. "10 Ways to Keep Your Class Interesting." ThoughtCo, www.thoughtco.com/ways-to-keep-your-classinteresting-4061719.

[3] Erenli, Kai. "The Impact of Gamification - Recommending Education Scenarios." International Journal of Emerging Technologies in Learning (IJET), Publisher: International Journal of Emerging Technology in Learning, Kassel, Germany, 31 Jan. 2013, www.learntechlib.org/p/45224/.

[4] Wilson, L.A and S. C. Dey, "Computational Science Education Focused on Future Domain Scientists," 2016 Workshop on Education for High-Performance Computing (EduHPC), Salt Lake City, UT, 2016, pp. 19-24, doi: 10.1109/EduHPC.2016.008

[5] "How Scientists Use Slack." Nature News, Nature Publishing Group, www.nature.com/news/how-scientistsuse-slack-1.21228.

[6] "Motivation in Education: What It Takes to Motivate Our Kids.” PositivePsychology.com, 1 Sept. 2020, positivepsychology.com/motivation-education/ 